\title{
Discurso de divulgação científica e canal Nerdologia no Youtube
}

\author{
Scientific dissemination an Nerdology channel \\ on Youtube
}

\author{
El Discurso de divulgación científica y el canal \\ de Youtube "Nerdologia"
}

Recebido em 21-06-2021

Modificado em 12-07-2021

Aceito para publicação em 29-07-2021

\section{d.}

\section{Ana Paula Simonaci Valentim}

Doutoranda em Memória Social pela Universidade Federal do Estado do Rio de Janeiro, Rio de Janeiro, Brasil. E-mail: anasimonaci@gmail.com

\section{Evelyn Goyannes Dill Orrico}

Doutora em Ciência da Informação (2001) pelo Instituto Brasileiro de Informação em Ciência e Tecnologia (IBICT). Professora Associada IV, atualmente Pró-Reitora de Pós-Graduação, Pesquisa e Inovação da Universidade Federal do Estado do Rio de Janeiro (UNIRIO), Brasil. E-mail: evelyn.orrico@unirio.br

\section{Eliezer Pires da Silva}

Doutor em Memória Social pela Universidade Federal do Estado do Rio de Janeiro, Brasil. Atualmente é arquivista do Arquivo Nacional e professor da Universidade Federal do Estado do Rio de Janeiro (UNIRIO). E-mail: eliezerpires@gmail.com

\section{Resumo}

A pesquisa problematizou a forma como o canal do YouTube, Nerdologia, expressa discurso de divulgação científica ao mesmo tempo em que constrói uma memória sobre ela. A contribuição deste trabalho para a memória social reside na compreensão do fenômeno da divulgação científica, por um viés que enfatiza o alcance do conhecimento científico junto à sociedade leiga, para além de sua circulação usualmente restrita à comunidade acadêmica. A abordagem teórico-metodológica assumida neste trabalho é interdisciplinar, articulando autores e acionando categorias conceituais de diferentes áreas. A metodologia é analítica, de cunho social, apoiada, fundamentalmente, na revisão de literatura sobre as temáticas envolvidas e uma abordagem empírica para identificar, em vídeos veiculados pelo canal, a presença de categorias indicativas de procedimento inovador, mas em constante diálogo com formas anteriores de divulgação da ciência. Concluímos que a participação da cultura nerd contribui para a renovação e ampliação da divulgação do saber científico na era contemporânea.

Palavras-chave: memória Social; divulgação científica; mídias contemporâneas; YouTube. 


\section{Introdução}

Este artigo apresenta parte dos resultados da pesquisa que realizamos sobre o modo como o canal Nerdologia expressa um discurso de divulgação científica e, ao fazê-lo, está construindo a memória da própria divulgação da ciência.

O vídeo analisado esclarece sobre vacina e lida com a desinformação relacionada ao assunto. Machado, Siqueira e Gitahy (2020) apontam desconfiança de uma parcela da população brasileira sobre efeitos de vacina. Esses autores observaram a desinformação que circula em canais brasileiros no YouTube ${ }^{1}$. O problema possui escala global: a Organização Mundial da Saúde considerou a desconfiança com a vacina como uma das maiores ameaças à saúde global em 2019 (World Health Organization, 2019).

Perceber que existe hoje um canal como o Nerdologia ${ }^{2}$ levou-nos a pesquisar como a divulgação científica vem ganhando novas formas, mas dialogando com uma memória discursiva de modos anteriores de divulgação. Consideramos que o canal Nerdologia é um objeto interessante para reflexões que buscam apontar e analisar esse novo cenário.

A proposta é pertinente e oportuna, especialmente se consideramos o contexto atual, em que emergem e se propagam, de forma expressiva, movimentos negacionistas em relação à ciência, tanto no Brasil quanto em outros países. A relevância social da temática é amplificada pelos embates em torno do papel da ciência como agente norteador de políticas públicas e atitudes individuais no contexto de pandemia em decorrência do novo coronavírus, que tão fortemente afetou as diversas dimensões da vida humana.

Para este artigo escolhemos o vídeo "Existe Perigo na Vacina?" para ilustrar as estratégias discursivas para se comunicar com o público, e entendemos que se cria um discurso, que não é o acadêmico, mas de divulgação científica, para argumentar, a título de exemplo, a favor do uso da vacina, com base em evidências científicas, históricas e jornalísticas.

A metodologia é analítica, de cunho social, apoiada, fundamentalmente, na revisão de literatura sobre as temáticas envolvidas e uma abordagem empírica para identificar, em vídeos veiculados pelo canal, a presença de categorias indicativas de procedimento inovador, mas em constante diálogo com formas anteriores de divulgação da ciência.

\footnotetext{
${ }^{1}$ O YouTube foi criado no Vale do Silício (Califórnia, Estados Unidos) em 2005, como uma plataforma para compartilhamento de vídeos amadores e artesanais. Desde 2006, tornou-se o segundo site mais popular da internet, com milhões de usuários (Burgess; Green, 2009:17).

${ }^{2}$ Disponível em https://www.youtube.com/nerdologia. Acesso em 10 mai. 2021
} 


\section{Canal Nerdologia no YouTube}

O canal Nerdologia foi criado em 2013 e faz parte da rede brasileira Amazing Pixel, network ${ }^{3}$ credenciada pelo YouTube para produção de vídeos e negociação de espaços comerciais na plataforma. Essa rede foi criada, entre outros, por Alexandre Ottoni, Deive Pazos e Gustavo "Guga" Mafra. A empresa agrega diversos canais - dos quais são exemplos o Jovem Nerd e o Nerdologia - e também vem ampliando seu foco para a comédia, com o 5algumacoisa e o Jacaré Banguela. Guga Mafra, que atua ainda na área comercial de sites populares como Casal Sem Vergonha e Papo de Homem, afirma, a respeito da Amazing Pixel: "Não estamos interessados em sair agregando canais, o foco é dar valor aos que temos". Nessa entrevista, concedida à IstoÉ Dinheiro em outubro de 2014, Mafra afirma ter faturado R\$ 1,5 milhão nos nove primeiros meses daquele ano. ${ }^{4}$

O canal Nerdologia, que conta com mais de 3 milhões de inscritos e mais de 300 milhões de visualizações, ganhou cerca de 4 mil dólares por mês nos últimos dois anos. ${ }^{5}$ Assim, podemos perceber que a atuação do canal não acontece livre de interesses financeiros, já que é preciso manter uma audiência que torne o projeto viável economicamente.

Atila Iamarino, criador e apresentador do canal, ganhou popularidade como divulgador de ciência em 2020, durante a pandemia do novo coronavírus, quando suas lives $^{6}$ voltadas a informar a população sobre o vírus, os sintomas da doença, o andamento das pesquisas e a situação do Brasil em relação aos demais países tiveram enorme audiência, alcançando milhões de visualizações. Desde 2014, no entanto, o Nerdologia já discutia assuntos relacionados a pandemia e virologia. Iamarino, biólogo e doutor em virologia pela Universidade de São Paulo (USP), cursou o pós-doutorado em genética molecular e de micro-organismos, também na USP, tendo concluído o pós-doutoramento na Universidade Yale, nos Estados Unidos. Crítico das políticas governamentais no que tange ao controle da pandemia e ao incentivo à pesquisa científica no país, Iamarino passaria a ser atacado por setores conservadores, empresários e negacionistas do coronavírus e da ciência. Sua participação no Roda Viva, no início da pandemia,

\footnotetext{
${ }^{3}$ Network é um termo que vem do inglês ("net" é rede e "work" é trabalho) e significa rede de relacionamentos ou rede de contatos.

${ }^{4}$ Disponível em https://www.istoedinheiro.com.br/noticias/mercado-digital/20141017/milionarios-youtube/200286? fbclid=IwAR3k_VVLM9VHhztKYdXP-Po2Rm_dIDB-SCd2JeYvKT0vfdtuis4L1FkJlnE. Acesso em 10 mai. 2021.

${ }^{5}$ Fonte: https://br.youtubers.me/nerdologia/youtube-quanto-ganha. Acesso em 10 mai. 2021

${ }^{6}$ Live em português significa, no contexto digital, "ao vivo". Na linguagem da Internet, a expressão passou a caracterizar as transmissões ao vivo feitas por meio das redes sociais. As lives são feitas de forma simples e ágil, geralmente sem limites de tempo de exibição ou de quantidade de espectadores.
} 
renderia a maior audiência da história do programa, de acordo com a jornalista da Folha de São Paulo, Cristina Padiglione ${ }^{7}$.

A primeira participação de Iamarino no programa Roda Viva foi em 2009, como entrevistador na bancada que conversou sobre H1N1 com o secretário de Saúde Luiz Roberto Barradas Barata. Nessa época, Iamarino mantinha um blog voltado à divulgação de informações sobre a epidemia, e também auxiliava a comunicação da OMS sobre o tema. ${ }^{8}$ Por intermédio desse espaço, ele ganhou visibilidade e foi convidado pelo Nerdcast - o podcast do Jovem Nerd - para falar sobre ciência na cultura pop. Em seguida, assumiu a liderança do Nerdologia, sendo responsável também pela apresentação dos programas. Em 2016, Iamarino passou a contar com a parceria de Filipe Figueiredo, apresentador do Xadrez Verbal, que assumiu os vídeos da área de história. Nesse momento, o canal teve sua periodicidade ampliada, de uma para duas postagens semanais.

$\mathrm{Na}$ entrevista feita por Verônica Soares da Costa (Iamarino, 2016) para o artigo "Atila Iamarino: 'Trato, principalmente, da ciência que sou': aspectos não-científicos em projetos de divulgação da ciência: entretenimento, cultura nerd e o perfil de público do Nerdologia”, Iamarino apresenta dados sobre o perfil de público do Nerdologia, destacando as temáticas abordadas e as marcas de classe e gênero no conteúdo do canal. Nessa entrevista Iamarino indica que, mesmo com a popularidade do canal, existem complexidades sociais que não permitem a difusão plena da cultura científica no Brasil (Iamarino, 2016).

Iamarino afirma que, diferente de outros canais de divulgação de ciência, o público do Nerdologia não foi construído do zero, visto que boa parte dos assinantes já acompanhavam o Jovem Nerd. Além disso, afirma que, muitas vezes, o título dos vídeos é pensado para atrair cliques, razão pela qual não fazem menção direta à ciência. Na referida entrevista, Iamarino comenta a popularidade do canal:

Eu prefiro ter um vídeo que é "os poderes da personagem X de quadrinhos" do que um vídeo sobre matéria escura, que muito menos gente sabe o que que é e não vai se interessar em clicar. Invariavelmente, a gente vai excluir alguma coisa, mas a opção é essa, é fazer uma coisa mais popular. O Nerdologia, por sorte, é popular. Eu não tinha um objetivo de assinantes, mas ele foi desenhado para ser popular, pelos temas que eu trato, pela maneira como eu falo e por quem produz o canal. Como o canal não é meu, é da Amazing Pixel, que é uma produtora de canais do YouTube, de duas pessoas que já trabalham com isso muito bem, que é o Alexandre e o Deive, ou Jovem Nerd e Azaghâl, eles desenharam o canal para ser uma coisa popular, no sentido de ter sucesso. Eles criaram o canal para isso (Iamarino, 2016:79).

\footnotetext{
${ }^{7}$ PADIGLIONE, Cristina. Audiência de Roda Viva com biólogo é a maior desde edição com Bolsonaro, em 2018. Telepad, in Folha de São Paulo. 31 mar 2020. Disponível em: https://telepadi.folha.uol.com.br/entrevista-combiologo-no-roda-viva-e-a-maior-desde-edicao-com-bolsonaro-em-2018/. Acesso em 10 mai. 2021

${ }^{8}$ Iamarino também participa do fórum ScienceBlogs, sendo responsável pelo portal no Brasil, que reúne 48 blogs referentes a temas de ciência, com foco em divulgação e discussão científica a partir de interações entre autores e/ou leitores.
} 
Iamarino afirma que o público do Nerdologia é majoritariamente masculino, formado por jovens de classe média de grandes metrópoles, com acesso à internet e YouTube. Os temas abordados, em geral, são voltados para adultos, considerando a complexidade do conteúdo. Além disso, afirma que se trata de um público que possui conhecimento básico de ciência, o que permite a ele supor que um assinante do canal já saiba o que seja DNA, por exemplo. Iamarino reconhece, portanto, que se trata de um canal voltado para as elites, e que a divulgação científica realizada pelo Nerdologia também é excludente, inclusive no que diz respeito à escolha dos tópicos a serem tratados.

Sobre o objetivo do canal, Iamarino afirma que a ideia é "tratar de ciência para quem não sabe que gosta de ciência", e que, para isso, articula a ciência a outros assuntos: "meu desafio semanal é esse: que tema de interesse popular eu vou tratar de maneira a colocar a ciência ali, para as pessoas se interessarem por ela." Outro norteador do planejamento de conteúdo é o tempo de duração do vídeo:

O Nerdologia, ao invés de tratar um tema de maneira mais longa, bem explicada, com calma, ele é meio frenético, às vezes. Eu falo de cinco, seis, dez conceitos ali dentro, cito dois, três livros, três artigos. Trato de um tema denso, que em cinco minutos não caberia, mas a ideia é essa: mostrar onde a ciência se insere para motivar as pessoas a buscarem mais aquilo em outro lugar (Iamarino, 2016:78).

Iamarino diz que trata de temas científicos que o interessam pessoalmente, e que, em geral, tem dificuldades para tratar de pesquisas brasileiras, considerando também a qualidade da divulgação científica no Brasil. É comum, portanto, que a pesquisa de conteúdo para o canal seja feita com base em referências internacionais, já sistematizadas e amplamente difundidas.

Por sorte, eu tenho um gosto bastante aberto em relação a temas, eu não falo só de biologia. Mas acaba sendo a ciência que eu consumo. Então, vai ser ciência internacional, porque $90 \%$ da informação que eu estou consumindo é na forma de áudio livro ou podcast, que é em inglês, na maioria das vezes. Acabo tendo muito contato com a ciência internacional. Eu tento incluir ciência brasileira e sempre que possível falar de alguém ou de alguma coisa, de algum evento ou situação relacionada ao Brasil. Quando eu fui falar sobre falta de água, fui entrevistar um professor de ecologia da USP para falar sobre isso. Quando falei de exoplanetas, fui procurar um astrônomo, da USP também, que trabalha com exoplanetas. Acaba sendo também em volta do meu umbigo, porque é onde eu estou, onde eu tenho acesso a isso. Quando eu vi que uma brasileira publicou um artigo, uma física publicou um artigo sobre transporte quântico de informação, eu fui entrevistar para fazer um vídeo sobre teletransporte. Então, às vezes, tem esse viés de eu pensar um tema que tem uma ciência legal sobre aquilo, que foi feita no Brasil, para falar a respeito. É difícil, bem difícil contextualizar, porque tem uma distância muito grande entre a ciência brasileira e a internacional. Quando eu falei sobre racismo, por exemplo, eu tenho pesquisas e pesquisas e pesquisas nos Estados Unidos falando sobre com que idade as crianças manifestam racismo, com quais grupos, dentro de quais classes... Falta o quê? Dados brasileiros. [...] Quando eu vou pegar uma pesquisa internacional, os caras já fizeram divulgação, já tem um texto, já tem um vídeo, já tem um clipe, é muito mais fácil (Iamarino, 2016:82). 
A relação com a cultura nerd ${ }^{9}$ é explícita no conteúdo do Nerdologia, que se apropria de diversos elementos desse universo para abordar assuntos científicos em seus vídeos. A referência à cultura nerd aparece no próprio nome do canal, que se autodenomina, no campo descritivo do YouTube "Sobre", como "Uma análise científica da cultura nerd!". Esta relação também é evidenciada pela filiação do canal ao portal Jovem Nerd.

O portal Jovem Nerd, que surgiu em 2002, é parte fundamental do universo cultural nerd no Brasil. A iniciativa da criação do blog parte também de Alexandre Otoni e Deive Pazoz, conhecidos, respectivamente, como Jovem Nerd e Azaghal, ambos listados pela revista Época ${ }^{10}$ entre as 100 pessoas mais influentes do Brasil e, pela Galileu, entre as 25 mais importantes da internet $^{11}$. Em 2006, o portal cresceu com a criação do NerdCast, podcast líder de audiência do Brasil, com marco histórico de 1 bilhão de downloads.

O portal Jovem Nerd se desdobrou em diversas subseções e em diferentes plataformas digitais, das quais destacamos as que têm presença em canais no YouTube: Jovem Nerd e Nerdologia. O canal Nerdologia ganhou tamanha repercussão que ultrapassou o canal Jovem Nerd no número de inscritos.

O caráter de divulgação científica também é claro na análise dos conteúdos do Nerdologia. O canal já surge com a proposta de abordar temas científicos. Podemos observar a utilização de recursos discursivos diversos para tratar de ciência, como, por exemplo, os apontados por Reale (2018) em um estudo semiológico sobre o canal: o uso de imagens para fortalecer discursos científicos, e o uso da aceleração ou redução da velocidade da câmera como metáforas para falar de relatividade do tempo.

O discurso que se inicia direcionado especificamente ao público nerd, aos poucos vai sendo modificado, tendo em vista maior alcance de público. Nos primeiros vídeos, a mensagem era claramente direcionada ao segmento nerd. Na primeira postagem, Atila Iamarino dirige-se ao público com a saudação “Olá, nerds!". Esta saudação repete-se até o episódio 12. Já nos seguintes, a palavra nerds foi excluída. Verificamos que, ao longo do tempo, os roteiros dos vídeos foram sendo adaptados, passando a incluir menos referências a esse grupo específico e, assim, amplificando a voz do canal para um público maior.

Bakhtin (1997) delineia gênero do discurso como instrumento com o qual formulamos sobre o passado, o presente e o futuro, podendo recordar ou esquecer por meio das formas enunciativas (Costa, 2017). A partir de Bakhtin (1997), entendemos que, no interior de um

\footnotetext{
${ }^{9}$ Entendemos Cultura nerd como repertório de práticas sociais ligadas ao consumo da cultura midiática, pervadido por uma ideia positiva de ciência, com forte influência sobre narrativas biográficas e identitárias, conforme Matos (2011), Galvão (2009) e Gomes (2015).

${ }^{10}$ Reportagem publicada pela revista Época em 17 de dezembro de 2011.

${ }^{11}$ Lista das 25 pessoas mais influentes da internet brasileira, publicada pela revista Galileu em 2013.
} 
gênero discursivo, os enunciados devem ser semelhantes e possuir características comuns e identificáveis, seja por repetições ou por diferenciações, de forma que possam ser reconhecidos e formar uma construção de sentido.

Para Zamboni (1997), os saberes científicos foram constituídos em uma linguagem hermética, ou seja, uso de termos incomuns nas falas cotidianas, ou mesmo termos técnicos, e com sua circulação restrita à academia. Caberia, portanto, à divulgação científica o papel de disseminar ao público leigo esse conhecimento. Conforme apontado pela autora em sua tese Heterogeneidade e subjetividade no discurso de divulgação científica (1997), acontece, na divulgação científica, a formulação de um novo discurso, que mantém articulação com campo científico, mas resulta de uma interferência a partir da reformulação da linguagem. Assim, Zamboni (2001:XVIII [Grifo nosso]) apresenta, logo na introdução da sua tese, aquilo que defende:

\footnotetext{
Muito menos corporificando a imagem de um discurso da ciência "degradado", que celebraria, de seu lugar vulgarizado, o discurso absoluto da ciência. Contrariamente a esse modo de ver, vejo no discurso da divulgação científica um gênero discursivo particular, distinto do gênero do discurso científico, autônomo tanto quanto qualquer outro discurso possa ser, e envolvente e cativante tanto quanto qualquer boa mercadoria colocada à venda deva ser.
}

Entendemos que essa divulgação é apresentar o conhecimento científico, de modo acessível ao público em geral, com objetivo de democratizar o acesso a esse conhecimento, aproximando ciência e sociedade (Sanchéz Mora, 2003; Costa Bueno, 2010).

Esse gênero do discurso de divulgação científica é uma esfera ou instância de produção discursiva em que fontes científicas são interpretadas e ingressam em um dialogismo inerente ao discurso para uma comunidade ou domínio. Comporta uma relativa estabilidade de enunciados, apesar de sujeito às mudanças sociais. Há um escopo: o conteúdo temático é a ciência. Existe um estilo: é uma elaboração explicativa e apoiada em evidências. (Orrico, 2015)

\section{Descrição comentada do vídeo do canal Nerdologia}

O vídeo "Existe Perigo na Vacina?”, do canal Nerdologia, se propõe a explicar o assunto. Esclarece como as vacinas são feitas e seu princípio de ação, contextualizando historicamente seu surgimento, os primeiros usos e aperfeiçoamentos. Desenvolve-se a partir do argumento de que a vacina não é tóxica, com base em explanações sobre os componentes timerosal, escaleno e alumínio. Combate o argumento de que vacina causa autismo, referindo-se à polêmica sobre o artigo médico de Andrew Wakefield, suas motivações e repercussões, reforçando que sua teoria foi refutada, sobretudo pelo jornalista Brian Deer. Utiliza como 
argumento de autoridade fatos jornalísticos, metodologias de pesquisas e fontes científicas. Conclui que não existem perigos nas vacinas e que o perigo está nas doenças que elas previnem. No encerramento, aponta dados anteriores às prevenções, reforçando os prejuízos causados pelas doenças.

Tabela 1: Vídeo Existe perigo na vacina?

\begin{tabular}{|c|c|}
\hline \multicolumn{2}{|c|}{ Identificação do vídeo } \\
\hline Título: Existe Perigo na Vacina? & Visualizações: 634.665 \\
\hline Data de postagem: 01/05/2014 & Duração: $6 \mathrm{~m} 54 \mathrm{~s}$ \\
\hline \multicolumn{2}{|c|}{ Adaptação da terminologia científica } \\
\hline \multicolumn{2}{|c|}{$\begin{array}{l}\text { O vídeo utiliza diversos termos científicos. Alguns ganham explicação etimológica } \\
\text { detalhada, tal como "patógeno" e "vacina". Muitos termos, no entanto, não são explicados, } \\
\text { como os componentes timerosal, etilmercúrio e escaleno; os elementos alumínio e mercúrio; } \\
\text { ou nomes de doenças como smallpox, catapora, sarampo e varíola. São feitas muitas } \\
\text { citações de fontes científicas e centros médicos em inglês, sem tradução. }\end{array}$} \\
\hline \multicolumn{2}{|c|}{ Interação com a audiência } \\
\hline \multicolumn{2}{|c|}{ Comentários: 4.051} \\
\hline Curtidas: 61.882 & Descurtidas: 1.082 \\
\hline Convite à participação: Sim & Resposta às dúvidas: Sim \\
\hline
\end{tabular}

Fonte: elaboração própria ${ }^{12}$.

Percebemos que este vídeo traz a definição da palavra "vacina". Faz uso de uma linguagem informal, ao mesmo tempo em que define palavras de cunho científico, como "patógenos". A palavra é detalhada na imagem, que traz uma legenda explicativa contendo o radical de sua origem - uma combinação de "páthos" e "genes". Podemos observar que esse é um recurso de divulgação científica, não só pela explicação da palavra científica, como também pela apresentação de imagens científicas de vírus e bactérias para o público.

O vídeo também traz uma contextualização histórica da vacina. Apresenta um conhecimento mais amplo para o público sobre a origem dos usos da vacina, e ilustra cientificamente como funciona o processo de reação do corpo que gera a imunidade, com foco principal no contexto histórico originário da vacina.

No sentido da contextualização histórica, o vídeo utiliza recursos como trazer à luz o nome do cientista Edward Jenner, e também esclarecer a origem da palavra científica "vacina", o que reafirma o caráter de divulgação científica presente no vídeo. Além disso, é reforçado visualmente o discurso de que, desde a origem da vacina, já havia polêmicas e protestos sobre o seu uso, não só no Brasil como no mundo. Destacamos que o vídeo busca demonstrar que o tema abordado - o perigo da vacina - não é novo, e sim historicamente recorrente.

\footnotetext{
${ }^{12}$ A identificação e análise também levou em consideração a elaboração sobre representações imagéticas propostas por Ribeiro, Oliveira e Wilke (2000).
} 
Percebemos que há uma explicação sobre a elaboração das vacinas, utilizando como exemplo a vacina da gripe e a da poliomielite, muito conhecida no Brasil pelo comercial da gotinha. Esse trecho do vídeo é muito rico no que diz respeito à divulgação científica, que fica evidente pela explicação sobre a vacina, mas principalmente pelas imagens de dois cientistas e suas descobertas, mostrando o laboratório e materiais de uso científico, como os frascos de vidro. Também merece destaque o uso do comercial da gotinha, que traz uma memória da cultura brasileira, visto que tanto o comercial quanto o personagem são muito conhecidos pelos brasileiros.

É interessante apontarmos o apelo imagético, demonstrado por meio de uma vacina puxando uma manifestação. A narrativa se refere ao conteúdo da vacina, muitas vezes constituído de escaleno para aumentar a resposta imunológica.

A apresentação da maior polêmica abordada no vídeo é sobre a vacina causar autismo. $\mathrm{O}$ trecho já se inicia com a pergunta e sua pronta resposta: "falso". Com uma explicação sobre a origem da polêmica, a partir do artigo do médico Andrew Wakefield, o quadro traz a divulgação científica tanto pela foto do artigo científico, demonstrando que foi refutado, como pela foto do médico. Imageticamente, também utiliza a foto do ator Jim Carrey e de Jenny McCarthy para demonstrar a comoção pública sobre o tema. A foto se refere ao protesto "Green our vaccines", realizado em 2008, nos Estados Unidos, contra a vacina, alegando que causaria autismo.

A argumentação contra o fato de vacinas causarem autismo traz essencialmente a apresentação do jornalista Brian Deer, que se dedicou a desmistificar a vacina combatendo o discurso de Andrew Wakefield. Neste trecho, busca-se reforçar para o público que existem argumentos factuais, como manchetes de jornais, comprovando que o artigo foi refutado.

A divulgação científica no vídeo é também reforçada quando, ao citar a pesquisa realizada pelo "Centers for Disease Control and Prevention", aborda de forma explicativa a metodologia científica apresentada no estudo.

Nas imagens, é apresentado o símbolo mundial do autismo. Este quadro realiza a importante tarefa de ampliar o conhecimento sobre o assunto para o público leigo, a partir de vídeos educativos e ilustrações que mencionam características do autismo.

A conclusão geral sobre o tema do vídeo é a de que não há qualquer perigo na vacina. Afirma que o perigo real seriam as doenças que as vacinas previnem. Por meio das imagens, demonstra que tanto nas Américas como na Europa as doenças que as vacinas previnem mataram grande parte de populações, apontando fatos como datas e números.

Traz dados populacionais entre os motivos para o surto de poliomielite, abordando também a erradicação do surto com o surgimento da vacina. Além disso, aponta que o sarampo 
não está extinto e que a vacina seria a solução. Nas imagens, aparecem dados sobre centros médicos, mapas de erradicação e gráfico.

No encerramento do vídeo, o apresentador indica o vídeo de outro youtuber que aborda assuntos científicos, o "Pirula", além do post do "Ecce Medicus", blog que trata também de assuntos científicos, especialmente de medicina. Interessante notar que o blog indicado se vincula ao fórum ScienceBlogs, do qual o apresentador Atila Iamarino também participa. Conclui também apresentando a periodicidade dos vídeos no canal, bem como o nome do canal e da plataforma YouTube.

\section{Características discursivas da divulgação científica do Canal Nerdologia}

Buscaremos neste momento observar as estratégias discursivas da divulgação científica que são operadas neste vídeo.

O título do vídeo traz em si uma pergunta: “Existe perigo na vacina?”. Entendemos que na plataforma YouTube, o título dos vídeos precisa seduzir, por meio de uma relação identitária, um público não apenas observador, mas interativo. Neste caso, podemos inferir que este seja chamativo por se tratar de um medo vigente na sociedade brasileira. Muitas vezes gerado pela desinformação sobre as vacinas.

Um marco importante que trata sobre essa memória do medo da vacina foi a revolta da vacina, em 1904. Nicolau Sevcenko ao publicar "A revolta da vacina: mentes insanas em corpos rebeldes", em 1983, foi o primeiro acadêmico a tratar em uma obra de cunho histórico sobre um assunto que se mostrava aparentemente esquecido pelos historiadores e que ilustra como esse medo ainda permanece no imaginário da população.

Assim, entendemos que, quando o vídeo traz o título tratando sobre esse tema, se torna atraente porque está se propondo a esclarecer um tema que há muito existe no imaginário e que continua fazendo parte do universo imaginário da população.

Dessa forma, o conteúdo traz uma série de informações esclarecedoras sobre o assunto, como a etimologia da palavra vacina; a contextualização histórica de sua origem e usos; as polêmicas históricas e protesto no Brasil e no mundo, destacando que é um tema recorrente; explica como são feitas; trata sobre os componentes químicos da vacina, como escaleno e mercúrio, explicando sobre o uso de cada um deles e confirmando que não são nocivos; esclarece sobre a vacina não ser causa de autismo e mostra os debates em torno dessa informação pela citação de pesquisas científicas. 
O vídeo cria um discurso a partir da tradução da linguagem de artigos e pesquisas de conteúdo científico. Assim, entendemos que este discurso participa da divulgação científica, considerando que o escopo é ciência e que a linguagem é traduzida para um público leigo. Percebemos que este é um discurso autônomo do científico, e que procura envolver e cativar, incorporando a definição de discurso de divulgação científica de Zamboni (2001).

O canal segue um padrão de enunciados semelhantes e características em comum, que são por meio de repetição, como a abertura do vídeo, o mesmo estilo de edição visual, com imagens e palavras em um quadro negro de fundo, e com a mesma forma de despedida, indicando a interação do público e respondendo a perguntas do vídeo anterior.

O vídeo traz imagens do universo nerd, como a da saudação feita com a mão pelo personagem Spock, símbolo da série Jornada nas Estrelas, somada à descrição "Nerd Power". Traz também o triângulo com o escrito "Lambda", referência ao símbolo que representa os nerds em uma competição no filme "A Vingança dos Nerds".

A inserção do vídeo na cultura nerd é marcada também por algumas menções à cultura pop, como a utilização de memes ${ }^{13}$, ou referências a desenhos animados como o Popeye, por exemplo. Outro fator relevante neste ponto é o entusiasmo com a ciência, um aspecto da cultura nerd que pode ser exemplificado pelo meme com a foto de um jovem e a legenda "Yeah, Science Bitch" ${ }^{\prime 14}$.

A figura do cientista, que costumava ser representada por sujeitos masculinos, de jaleco e óculos, aqui ganha uma nova roupagem: camisas de malha, sobreposta por uma camisa quadriculada e uma calça jeans, dentro de uma imagem definidora dentro da cultura nerd. $\mathrm{O}$ apresentador precisa incorporar então a figura do nerd, que não apenas entende de ciência, mas que também é um especialista no universo que vigora nesta cultura.

Do ponto de vista narrativo trata-se da exibição de conteúdos que satisfazem uma busca por conhecimento científico movido pela curiosidade, mas também é um reforço de identidade, que engloba, dentro desta cultura, uma visão de mundo.

Percebemos que o uso de referências a cultura nerd é utilizado no discurso do vídeo, que busca democratizar o conhecimento sobre ciência. Conforme vimos em Orrico (2015), o discurso de divulgação científica além de ter o escopo científico opera nesse diálogo com uma

\footnotetext{
${ }^{13}$ A expressão meme é usada para descrever um conceito de imagem, vídeos, GIFs e/ou relacionados ao humor, que se espalha via internet. $\mathrm{O}$ termo é uma referência ao conceito de memes, que se refere a uma teoria ampla de informações culturais criada por Richard Dawkins em seu best-seller de 1976, o livro O Gene Egoísta.

14 "Yeah Science, Bitch" (Sim, Ciência, Vadia!) é uma expressão associada ao personagem Jesse Pinkman, da série dramática de televisão Breaking Bad. Na web, a frase é frequentemente usada para expressar humoristicamente o entusiasmo de alguém por novas descobertas e aplicações práticas do conhecimento científico. A origem do meme de Pinkman foi no episódio da série, onde o protagonista Walter White informa ao Pinkman que descobriu um método alternativo para cozinhar metanfetamina que não requer pseudoefedrina como um ingrediente, ao qual Pinkman exclama "Sim, Sr. White! Sim, ciência!" na emoção.
} 
comunidade. Observamos que este discurso contempla essa conceituação e ingressa em um dialogismo inerente a linguagem voltada para a comunidade nerd.

Os vídeos trazem ainda uma estrutura análoga a discursos passados de divulgação científica: há o aspecto de curiosidade, o tom didático e explicativo, as narrativas esclarecedoras envolvendo mistérios científicos. Agora, porém, com uma nova roupagem midiática.

Permeado por tons urbanos, o conteúdo é realizado por um canal de uma megalópole, São Paulo. Embora o vídeo seja feito para atingir a um público nacional, as referências estão relacionadas a exibições de cinema e séries, além de quadrinhos. Este discurso aqui se apresenta para um público com acesso à internet, situados em um universo onde a ciência carrega diversas outras imagens, embebidas de entretenimento da indústria cultural. Isso modifica a narrativa de sua apresentação. Encontra-se então uma memória reconhecida em uma nova aparência e traduzida a partir de símbolos carregados de novos significados.

\section{Conclusão}

Ampliamos nossa compreensão sobre o conceito de discurso de divulgação científica e conseguimos perceber características desse gênero discursivo no vídeo "Existe Perigo na Vacina?".

Por intermédio do olhar aprofundado sobre o discurso do vídeo, pudemos entender seu funcionamento e perceber que há um fio que remete a construções de memórias pelos discursos de divulgação científica, agora com características de linguagem que participa da cultura nerd.

O vídeo utiliza recursos de linguagem para atrair o público tendo em vista desmistificar os medos em relação às vacinas, e utiliza informações de base científica traduzidas em tom cativante para acomodar fontes científicas e as traduzir por uma linguagem acessível para um público leigo e abrangente.

O discurso de divulgação científica é repaginado em novas mídias, em um novo imaginário, além de um novo alcance e interação. Assim, podemos entender que o canal do YouTube, Nerdologia, expressa discurso de divulgação científica e ao mesmo tempo constrói uma memória sobre ela.

A contribuição deste trabalho para a memória social reside na compreensão do fenômeno da divulgação científica, por um viés que enfatiza o alcance do conhecimento científico junto à sociedade leiga, para além de sua circulação usualmente restrita à comunidade acadêmica.

Concluímos que a participação da cultura nerd contribui para a renovação e ampliação da divulgação do saber científico na era contemporânea. 


\section{Referências}

BAKHTIN, Mikhail (1997), Estética da criação verbal. 2. ed. São Paulo, Martins Fontes.

BUENO, Wilson Costa (2010), "Comunicação científica e divulgação científica: aproximações e rupturas conceituais". Informação \& Informação, v. 15, pp. 1-12 [Consult. 12-05-2020]. Disponível em https://www.brapci.inf.br/index.php/article/download/14078

BURGESS, Jean. GREEN, Joshua (2009). YouTube e a Revolução Digital: como o maior fenômeno da cultura participativa transformou a mídia e a sociedade. São Paulo, Aleph, 2009.

GALVÃO, Danielle (2009), "Os nerds ganham poder e invadem a TV”. Revista Científica Intr@ciência, v.1, n; 1, pp. 34-41 [Consult 12-05-2020].

Disponível em https://uniesp.edu.br/sites/_biblioteca/revistas/20170531154050.pdf

GOMES, Paula (2015), O papel da identidade no encontro da cultura com a tecnologia: Um estudo sobre o site Omelete e seus projetos. 2015. Dissertação (mestrado em Comunicação Social) - Faculdade de Comunicação da Universidade Metodista de São Paulo, São Bernardo do Campo.

IAMARINO, Atila. Entrevista I. [jun. 2016], Entrevista concedida a Verônica Soares da Costa. Belo Horizonte.

MACHADO, Dayane F. T. SIQUEIRA, Alexandre F.; GITAHY, Leda (2020), "Natural stings: selling distrust about vaccines on brazilian youtube". Frontiers Research Foundation [Consult. 10-04-2020]. Disponível em https://www.frontiersin.org/articles/10.3389/fcomm.2020.577941/full

MATOS, Patrícia (2011), “O Nerd virou cool: identidade, consumo midiático e capital simbólico em uma cultura juvenil em ascensão". Anais... INTERCOM - Congresso de Ciências da Comunicação na Região Sudeste, 16, São Paulo [Consult. 10-04-2020]. Disponível em http://www.intercom.org.br/papers/regionais/sudeste2011/resumos/R24-1149-1.pdf

ORRICO, Evelyn (2015), “A memória da divulgação científica: um discurso informacional”. Revista Morpheus - Estudos Interdisciplinares em Memória Social, v. 8, n. 14, pp. 114-130 [Consult. 02-012021]. Disponível em http://www.seer.unirio.br/index.php/morpheus/article/view/4827

REALE, Manuella V. (2018), O sabor do saber: divulgação científica em interação no YouTube. 2018. Dissertação (mestrado em Comunicação e Semiótica) - Faculdade Pontifícia Universidade Católica de São Paulo, São Paulo.

RIBEIRO, Leila B.; WILKE, Valéria C. L.; OLIVEIRA, Carmen I. C. (2000), "O filme como objeto de análise informacional: o espectador e sua leitura". Anais... ENCONTRO NACIONAL DE PESQUISA EM CIÊNCIA DA INFORMAÇÃO, Brasília, UnB.

SANCHEZ MORA, Ana Maria (2003), A divulgação da ciência como literatura. Casa da Ciência Centro Cultural de Ciência e Tecnologia da Universidade Federal do Rio de Janeiro, Editora da UFRJ.

WORLD HEALTH ORGANIZATION (2019), Ten Threats to Global Health in 2019. WHO Newsroom.

ZAMBONI, Lilian M. S (2001), Cientistas, jornalistas e a divulgação científica: subjetividade e heterogeneidade no discurso da divulgação científica. Campinas, Editora Autores Associados.

ZAMBONI, Lilian M. S (1997), Heterogeneidade e subjetividade no discurso de divulgação científica. Tese (Doutorado em Linguística) - Instituto de Estudos da Linguagem da Universidade Estadual de Campinas, Campinas. 


\begin{abstract}
The research analyzes how the YouTube channel, Nerdologia, is an expression of scientific dissemination at the same time that it builds a memory of it. The contribution of this work to the field of social memory lies on understanding the phenomenon of scientific dissemination, with an emphasize of the reach of scientific knowledge to the lay society, in addition to its circulation, which is usually restricted to academic community. This work proposes an interdisciplinary theoretical and methodological approach, articulating authors and triggering conceptual categories from different areas. The analytical methodology is based, fundamentally, on the literature review on the themes involved and an empirical approach in order to identify, in videos broadcasted by the channel, the presence of categories which could indicate an innovative procedure but still in constant dialogue with previous forms of dissemination of science. The article concludes suggesting that nerd culture in these activities contributes to the renewal and expansion on disseminating scientific knowledge in the contemporary era.
\end{abstract}

Keywords: social memory; scientific divulgation; contemporary media; YouTube.

\title{
Resumen
}

La investigación cuestionó cómo el canal de YouTube "Nerdologia" expresa un discurso de divulgación científica mientras que, al mismo tiempo, construye una memoria sobre ella. La contribución de este trabajo a la memoria social radica en comprender el fenómeno de la difusión científica, desde una mirada que enfatiza el alcance del conocimiento científico en grupos sociales sin instrucción en el área, yendo más allá de la circulación habitualmente restringida a la comunidad académica. El enfoque teóricometodológico adoptado en este trabajo es interdisciplinario, articulando autores y valiéndose de categorías conceptuales de diferentes áreas. La metodología es analítica, basada, fundamentalmente, en la revisión de la literatura sobre los temas abordados y en un enfoque empírico para identificar, en los vídeos difundidos por el canal, la presencia de categorías que expresen un procedimiento innovador, pero en constante diálogo con formas tradicionales de difusión de la ciencia. Concluimos que la participación de la cultura nerd contribuye a la renovación y expansión de la difusión del conocimiento científico en la era contemporánea.

Palabras clave: memoria social; divulgación científica; medios de comunicación contemporáneos; YouTube. 